\title{
Inhibition of Human Hemoglobin Autoxidation by Sodium n-Dodecyl Sulphate
}

\author{
Dayer Mohammad Reza, Moosavi-Movahedi Ali Akbar*, Norouzi Parviz", \\ Ghourchian, Hedayat-Olah and Safarian Shahrokh \\ Institute of Biochemistry and Biophysics, University of Tehran, Iran \\ 'Department of Chemistry, Faculty of Science, University of Tehran, Iran.
}

Received 11 February 2002, Accepted 16 April 2002

\begin{abstract}
The effect of sodium n-dodecyl sulphate (SDS) on hemoglobin autoxidation was studied in the presence of a $100 \mathrm{mM}$ phosphate buffer (pH 7.0) by different methods. These included spectrophotometry, fluorescence technique, cyclic voltametry, differential scanning calorimetry, and densitometry. Spectroscopic studies showed that SDS concentrations up to $1 \mathrm{mM}$ increased deoxy-, decreases oxy-, and had no significant effect on the met- conformation of hemoglobin. Therefore, a SDS concentration up to $1 \mathrm{mM}$ increased the deoxy form of hemoglobin as the folded, compact state and decreases the oxy conformation. The turbidity measurements and differential scanning calorimetry techniques indicated a more stable conformation for hemoglobin in the presence of SDS up to $1 \mathrm{mM}$. Electrochemical studies also confirmed a more difficult oxidation under these conditions. The induction of the deoxy form in the presence of SDS was confirmed by densitometry techniques. The compact structure of deoxyhemoglobin blocks the formation of met-conformation in low SDS concentrations.
\end{abstract}

Keywords: Autoxidation, Folding, Hemoglobin, SDS, Stability

\section{Introduction}

Hemoglobin is a tetrameric allosteric protein that consists of two alpha and two beta subunits that are arranged around a central cavity with pseudodiad symmetry (Boyiri et al.,1995). Hemoglobin normally has three conformational structures. These are the oxy-, deoxy- and met-conformations. In the oxy-conformation, hemoglobins heme center is in the reduced form and has the relaxed (R) conformation. However, the

*To whom correspondence should be addressed.

Tel: 9821-6403957; Fax: 9821-6404680

E-mail: moosavi@ibb.ut.ac.ir heme group has the tense (T) conformation in the deoxy form. Finally, in the met-conformation, the heme center is in an oxidized state and has a relaxed-like conformation (Banerjee and Cassoly, 1969; Ho et al., 1982; Mizukoshi et al., 1982; Bunn and Forget, 1986;). The shift from the R to T quaternary structure is primarily triggered by displacement of the $\mathrm{N \varepsilon}$ nitrogen of the proximal histidine relative to the mean plane of the porphyrin ring. In deoxyhemoglobin, this distance is 2.7 $\mathrm{A}^{\mathrm{o}}$, whereas, it is $2.0 \mathrm{~A}^{\mathrm{o}}$ in oxyhemoglobin. In methemoglobin, the $\mathrm{N} \varepsilon$-porphyrin distance is intermediate, $2.3 \pm 0.01 \mathrm{~A}^{\circ}$, and is expected to undergo a shift from the $\mathrm{R}$ to $\mathrm{T}$ quaternary structure more readily than oxyhemoglobin (Bunn and Forget, 1986). Normally, Fe (II) is essential for hemoglobin function in the reduced state, because Fe (III) is incapable of binding oxygen in the oxidized state (Bunn and Forget, 1986).

The hemoglobin solution is slowly oxidized with time, which is referred to as autoxidation. This process causes the denaturation of hemoglobin, since globin has a much lower affinity for ferric hemin than the reduced form (Brantley et al., 1993). The rate at which autoxidation occurs is markedly dependent on hemoglobin's quaternary structure. The more deoxy or tense the form, then the more autoxidation occurs. Therefore, the presence of ligands like 2,3-diphosphoglycerate (DPG) and inositol hexaphosphate (IHP) increases the concentration of the deoxy molecule that enhances the autoxidation process (Mansouri and Winterhalter, 1974; MacDonald and Charache, 1982; Bunn and Forget, 1986; Dong et al., 1995). The rate at which deoxyhemoglobin is oxidized is about two times higher than the rate of oxyhemoglobin (Mansouri and Winterhalter, 1974; Ho et al., 1982; Bunn and Forget, 1986). Recent evidence suggests that the anion-assisted autoxidation of hemoglobin requires deoxyhemoglobin in the presence of a small amount of oxygen (Bunn and Forget, 1986). The oxidation reaction causes a transition from the five coordinated deoxy- to the six coordinated methemoglobin in which a water molecule 
occupies the sixth coordination site, which is occupied by oxygen in oxyhemoglobin (Stargardt, Awkridge and Lanrum, 1978; Dickerson et al., 1993; Bonaventura et al., 1998). Relaxation experiments showed that in this transition a water molecule is needed (Ho et al., 1982) and the resultant hemoglobin is called aquomet-hemoglobin (Ho et al., 1982; Bunn and Forget, 1986; Schlereth and Mäntele, 1992). In contrast to deoxyhemoglobin, methemoglobin in the aquomet form has the same conformation as oxyhemoglobin, which is the relaxed or R conformation (Bunn and Forget, 1986; Schlereth and Mäntele, 1992). However, earlier investigators showed that hemoglobin oxidation is more difficult when the conformational equilibrium is shifted toward the $\mathrm{T}$ state by a preferential anion binding (Kilmartin 1973; Faulkner, Bonaventura and Crumbliss, 1995; Bonaventura et al., 1998; Safo et al., 2001).

Hemoglobin undergoes an irreversible heterogeneous electron transfer reaction at bare metallic electrodes, such as gold (Kilmartin, 1973; Faulkner, Bonaventura and Crumbliss, 1995). The quasi-reversible electrochemical reaction proceeds with reaction rates of the oxidation step that are much slower than the reduction step (Dickinson and Chien, 1975; Schlereth and Mäntele, 1992). Therefore, the use of electrochemical methods may provide a powerful technique for a better understanding of the oxidative behavior of hemoglobin (Geraci and Sada, 1972).

Sodium n-dodecyl sulphate (SDS) is an anionic detergent that is known as a denaturant. In concentrations greater than $2 \mathrm{mM}$, SDS unfolds most proteins (Moosavi-Movahedi, Nazari and Saboury, 1997; Moosavi-Movahedi, Naderi and Farzami, 1994; Bordbar, Moosavi-Movahedi and Saboury, 1996). We have also shown that a few proteins are compacted in the presence of SDS at low concentrations $(<2 \mathrm{mM})$ (Moosavi-Movahedi et al., 1989; Moosavi-Movahedi, 1994; Moosavi-Movahedi and Ghobadi, 1991). We also reported that the effect of surfactants, such as SDS on the protein denaturation, is predominantly an electrostatic contribution (Nazari, Saboury and Moosavi-Movahedi, 1997). In the present work, our goal is to show that SDS prevents the autoxidation of hemoglobin at low concentrations.

\section{Materials and Methods}

Sodium n-dodecyl sulphate with a purity of $99 \%$ was obtained from Sigma. CM-Sephadex and Sephadex G-25 were obtained from Pharmacia Fine Chemicals. The other reagents were of analytical grade. All of the solutions were prepared with double-distilled water.

Hemoglobin preparation Human adult hemoglobin ( $\mathrm{HbA})$ was prepared from human red blood cells of healthy donors, according to the method of Williams et al. (William and Tsay, 1973). They were stripped of anions according to the procedure that was reported by Riggs (Riggs, 1981). The heparinized blood was washed twice with ten volumes of isotonic saline. The washed, packed cells were lysed with an equal volume of deionized water.
The stroma was removed after $1 \mathrm{~h}$ at $0^{\circ} \mathrm{C}$ by centrifugation at $10,000 \mathrm{rpm}$ for $25 \mathrm{~min}$. The solution was applied to a Sephadex G25 column $(1.5 \times 45 \mathrm{~cm})$ that was equilibrated with a $100 \mathrm{mM}$ phosphate buffer $\mathrm{pH}$ 7.0. Elution was carried out with a $0.1 \mathrm{M}$ phosphate buffer $\mathrm{pH} 7.0$ at a flow rate of $25 \mathrm{ml}$ per h (Berman, Benesch, and Benesch (1971)). For further purification of human adult hemoglobin, we used a CM-Sephadex cation exchanger at $\mathrm{pH}$ 6.5 .

Spectroscopic experiments The equation of Benesch, et al. (Benesch, Benesch, and Yung, 1973) was optimized for the present experiments at $\mathrm{pH}$ 7.0. The concentrations of oxy-, deoxy-, and met-forms of hemoglobin were determined using hemoglobin samples $(4-6 \mathrm{mg} / \mathrm{ml}$ ) in a $100 \mathrm{mM}$ phosphate buffer $\mathrm{pH}$ 7. The absorbance at 560, 576, and $630 \mathrm{~nm}$ were recorded on a Shimadzu model UV-3100 (Japan) spectrophotometer and a thermostaticallycontrolled cell compartment with a Haak D8 water bath. The samples were kept in a closed cuvette at $27^{\circ} \mathrm{C}$. The following equation were used for calculation of the hemoglobin conformers' concentration:

$$
\begin{aligned}
& {[\text { oxy }]=\left(1.0154 \mathrm{~A}_{576}-0.2772 \mathrm{~A}_{630}-0.742 \mathrm{~A}_{560}\right) \times 10^{-4} \mathrm{Mol}} \\
& {[\text { deoxy }]=\left(1.335 \mathrm{~A}_{560}-0.7356 \mathrm{~A}_{576}-0.6254 \mathrm{~A}_{630}\right) \times 10^{-4} \mathrm{Mol}} \\
& {[\text { met }]=\left(2.6828 \mathrm{~A}_{630}+0.174 \mathrm{~A}_{576}-0.3414 \mathrm{~A}_{560}\right) \times 10^{-4} \mathrm{Mol}}
\end{aligned}
$$

The spectra were recorded after 2 min upon addition of SDS to the $\mathrm{Hb}$ samples. The concentration of hemoglobin solutions in all of the experiments was in the $\mathrm{mM}$ range. This concentration was high enough (i.e., $\geq 100 \mu \mathrm{M}$ heme) to avoid the formation of a considerable amount of dimers, which should always be $\leq 5 \%$ (Coletta et al., 1993).

Fluorescence experiments A Hitachi model MPF-4 Fluorescence spectrophotometer that was equipped with a temperature controller Prothermo bath model NTB-211 was used for all of the fluorescence experiments. The excitation wavelength was adjusted to $295 \mathrm{~nm}$ in all of the experiments, which was specific for the excitation of the Trp residues of the protein structure. Emission spectra were recorded between the wavelengths of 330 to $400 \mathrm{~nm}$ at the bandwidth of $10 \mathrm{~nm}$. Comparison of the emission spectra was performed with regard the maximum fluorescence that was recorded at the $330 \mathrm{~nm}$ and $328 \mathrm{~nm}$ that were registered for fluorescence and quenching experiments, respectively. Hemoglobin samples were provided in the range of 4$6 \mathrm{mg} / \mathrm{ml}$ in a phosphate buffer $(100 \mathrm{mM}, \mathrm{pH} 7)$ at $27^{\circ} \mathrm{C}$.

Turbidity measurements The absorbance measurements of the samples were carried out at a 700-nm wavelength versus temperatures up to $70^{\circ} \mathrm{C}$ when using an UV-VIS spectrophotometer (Shimadzu model UV-3100) as the turbidity index. The hemoglobin samples had a $4-6 \mathrm{mg} / \mathrm{ml}$ concentration in a phosphate buffer (100 mM, pH 7).

Densitometric experiments Densitometry model DMA 58 (Austria) was used for density measurements of the adult human hemoglobin samples. Hemoglobin samples were thoroughly deionized by dialyzing against distilled-deionized water and passing through Sephadex G-25 prior to the experiments. Samples were prepared in a $10 \mathrm{mM}$ phosphate buffer and deoxygenated by 
degassing of solution with an inert gas. The partial specific volume of the hemoglobin samples in a given SDS concentration were obtained at $27^{\circ} \mathrm{C}$ using at least 10 samples with different concentrations of hemoglobin for each SDS concentration, according to the method reported previously (Arakawa and Timasheff, 1982). The density of these samples was converted to the apparent specific volume $\left(\varphi_{\text {app }}\right)$ by the following equation:

$$
\varphi_{\mathrm{app}}=\frac{1}{\rho_{0}}\left(1-\frac{\Delta \rho}{\mathrm{c}_{2}}\right)
$$

where $\Delta \rho$ is the difference between the densities of the protein solution and solvent, and $c_{2}$ is the protein concentration in $\mathrm{g} / \mathrm{ml}$. Extrapolation of $\varphi_{\text {app }}$ to zero protein concentration gives the partial specific volume.

Electrochemical experiments The electrochemical experiments were performed in the cyclic voltametry mode on a Metrohm Analysis Model 741-electrochemistry system. Gold and carbon paste electrodes were used in a parallel manner. The carbon paste electrode (1 $\mathrm{mm}$ in diameter) was made by mixing equal volumes $(50 / 50 \mathrm{v} / \mathrm{v})$ of carbon powder and hemoglobin. The reference $\mathrm{Ag} /$ $\mathrm{AgCl} / 3 \mathrm{MKCl}$ electrode and the counter electrode (a Pt wire, $0.5 \mathrm{~mm}$ in diameter and $2 \mathrm{~cm}$ long) were sealed in a glass tube. All of the electrochemical measurements were carried out under anaerobic conditions. Oxygen was removed under mild stirring by a gentle flow of pure argon. The range of potential scan was -500 to $250 \mathrm{mV}$ with the scan rate of $12 \mathrm{mV} / \mathrm{sec}$.

Differential Scanning Calorimery (DSC) investigations DSC studies were carried out on an ultrasensitive Scal 1 microcalorimeter (Russia). The sample cell was filled with protein solutions; the reference cell was filled with a buffer solution that contained all of the sample constituents, except the protein. The cells were carefully filled to avoid air bubbles. DSC scans were performed in the temperature range of $20-80^{\circ} \mathrm{C}$. The hemoglobin concentration in all of the sample solutions was $1 \mathrm{mg} / \mathrm{ml}$; the heating rate was $2 \mathrm{~K} / \mathrm{min}$.

\section{Results and Discussion}

Fig. 1A shows the SDS effect on the formation of hemoglobin species (oxyhemoglobin, deoxyhemoglobin and methemoglobin) in solution. The deoxyhemoglobin, oxyhemoglobin, and methemoglobin forms increased, decreased, or were not significantly altered due to the increasing SDS concentration (up to $1 \mathrm{mM}$ ). The autoxidation process at room temperature is very slow (data not shown). Because the rate constant of autoxidation that was previously reported is temperature dependent (Zavodnik, Piletskaia and Stepuro, 1992); therefore, the experiment was performed at $50^{\circ} \mathrm{C}$ for enhancing this process (Fig. 1B). This figure shows the time course formation slope of methemoglobin at a $1 \mathrm{mM}$ concentration of SDS in its minimal level. This indicates that the met formation or autoxidation is inhibited by a SDS concentration up to $1 \mathrm{mM}$.
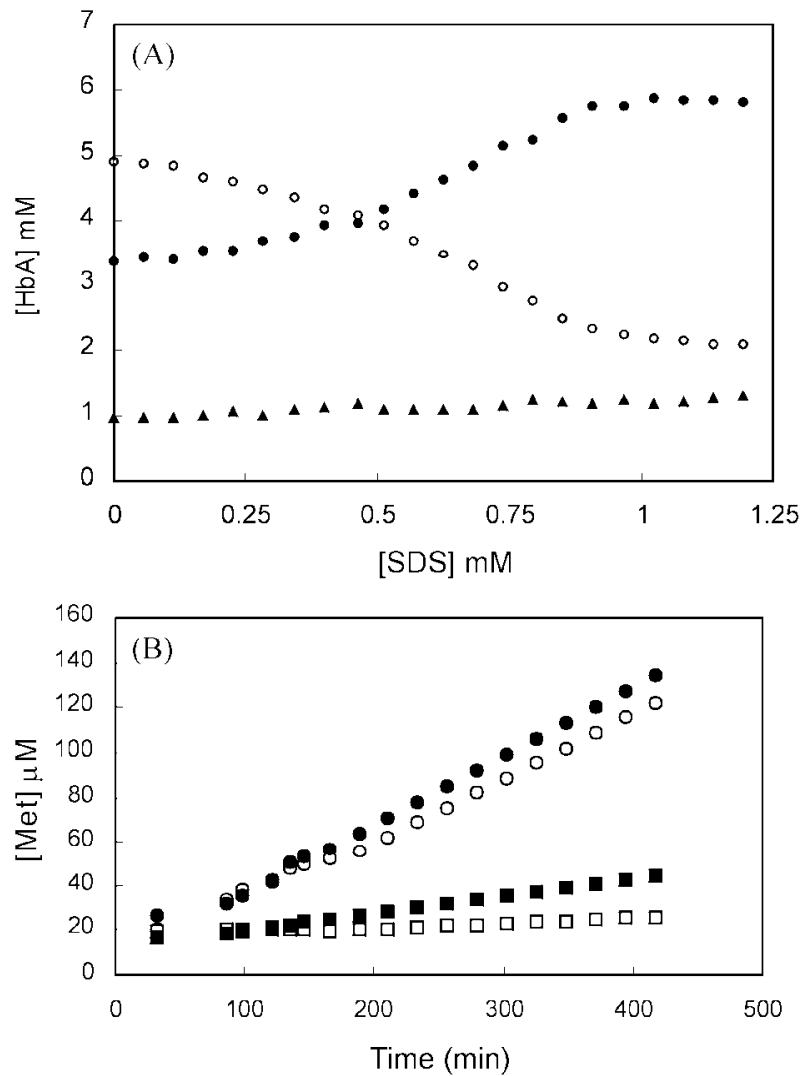

Fig. 1. (A) Concentration of the Oxy-, Deoxy-, and Metconformation of hemoglobin in different SDS concentrations. The hemoglobin concentration sample was $4 \mathrm{mg} / \mathrm{ml}$ in a $100 \mathrm{mM}$ phosphate buffer, pH 7 at $27^{\circ} \mathrm{C}$. Filled circles, Deoxy; open circles, Oxy; filled triangles, Met. (B) Time-course formation of met hemoglobin at $50^{\circ} \mathrm{C}$. Open square, $1 \mathrm{mM}$ SDS; filled square, $0 \mathrm{mM}$, open circle, $1.5 \mathrm{mM}$ SDS; filled circle, $2.5 \mathrm{mM}$ SDS.

These electrochemical studies focused on the SDS effect on the cyclic voltamogram of hemoglobin. Fig. 2 shows the recorded voltamograms, a to e, of the hemoglobin solution, where the SDS concentrations are 0, 0.4, 1, 1.5, and $2.5 \mathrm{mM}$, respectively. A SDS concentration increase, up to $1 \mathrm{mM}$, caused the potential of the peaks, $\mathrm{E}_{\mathrm{p}}$, to shift to potentials that are more positive; whereas, going to higher SDS concentrations had the opposite effect. Therefore, because $\mathrm{E}_{\mathrm{p}}$ is directly related to $\mathrm{E}^{\mathrm{o}}$ (the redox potential of the protein), then the electrochemical oxidation of hemoglobin becomes more difficult in this concentration range (up to $1 \mathrm{mM}$ SDS). It was previously reported that the effectors, which shift the quaternary conformation of hemoglobin toward the deoxy state, are concomitant with shifts in the redox potential to more positive potentials (Bonaventura et al., 1998). Comparison of those results with our cyclic voltammetric data suggests that SDS at low concentrations shifts the hemoglobin conformation to a more folded state. Moreover, in previous electrochemical studies (Antonini and Brunori, 1971; Gary and Gibson, 1971; Desbois and Bangerjee, 1975), the 


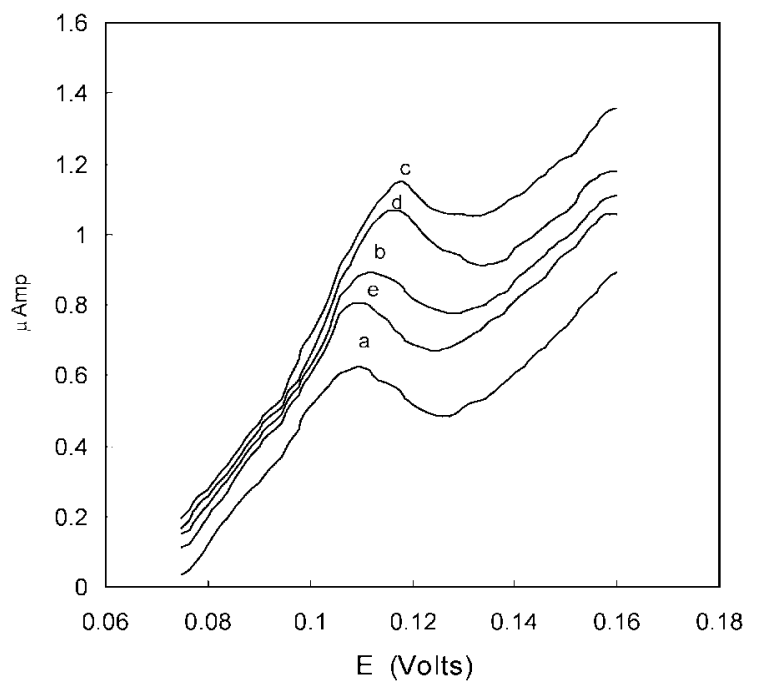

Fig. 2. Anodic peak of hemoglobin cyclic voltamogram (microampere against volts) in the presence of SDS. Gold and carbon paste electrodes ( $1 \mathrm{~mm}$ in diameter) were used separately as working electrodes, and the reference electrode $\mathrm{Ag} / \mathrm{AgCl} /$ $3 \mathrm{MKCl}$ and the counter electrode $\mathrm{Pt}$ wire $(0.5 \mathrm{~mm}$ in diameter and $2 \mathrm{~cm}$ long) were used. The hemoglobin concentration sample was $4 \mathrm{mg} / \mathrm{ml}$ in a $100 \mathrm{mM}$ phosphate buffer, $\mathrm{pH} 7$ at $27^{\circ} \mathrm{C}$. a) $0 \mathrm{mM}$ SDS; b) $0.4 \mathrm{mM}$ SDS; c) $1 \mathrm{mM}$ SDS; d) $1.5 \mathrm{mM}$ SDS; e) $2.5 \mathrm{mM}$ SDS.

potential shift was discussed, based on the chemical equilibrium shift from the oxy to deoxy conformations by a concentration change of some compounds in the solution, although there is a trend between our results and previous ones. Here, the observed $\mathrm{E}_{\mathrm{p}}$ shift toward the less positive potentials, can be discussed, based on the unfolding of the protein (Schlereth and Mäntele, 1992). The increase in $i_{p}$ could be the result of the existence of a multilayer of weakly adsorbed hemoglobin on the electrode surface. The consequence would be a decrease in the volume of the first adsorbed layer, which would create the possibility of oxidation for the second adsorbed layer of hemoglobin (Satoh and Shikama, 1981; Wallace et al., 1982; Baldwin, 1988; Skoog and Leary, 1992). It was previously reported that an increase in $i_{p}$ is the result of an increased concentration of more folded hemoglobin at the electrode surface (Schlereth and Mäntele, 1992). The peak current, $i_{p}$, is a criteria of electron transferring. The electron transfer reactions of redox proteins are accelerated by surface active compounds, such as SDS, which carry the same charge as the redox protein (Brabec, 1996). Hemoglobin conditions in the experiment ( $\mathrm{pH}$ 7) had a negative net charge. As mentioned previously, SDS (a surfactant with a negative charge) at a $1 \mathrm{mM}$ concentration folds the hemoglobin, decreases its volume, and increases the possibility of oxidation at the electrode surface (increase in $i_{p}$ ). Therefore, the increased and decreased $i_{p}$ agree with the SDS folding/unfolding effect on hemoglobin. On the other hand, the SDS-hemoglobin interaction increases the density of

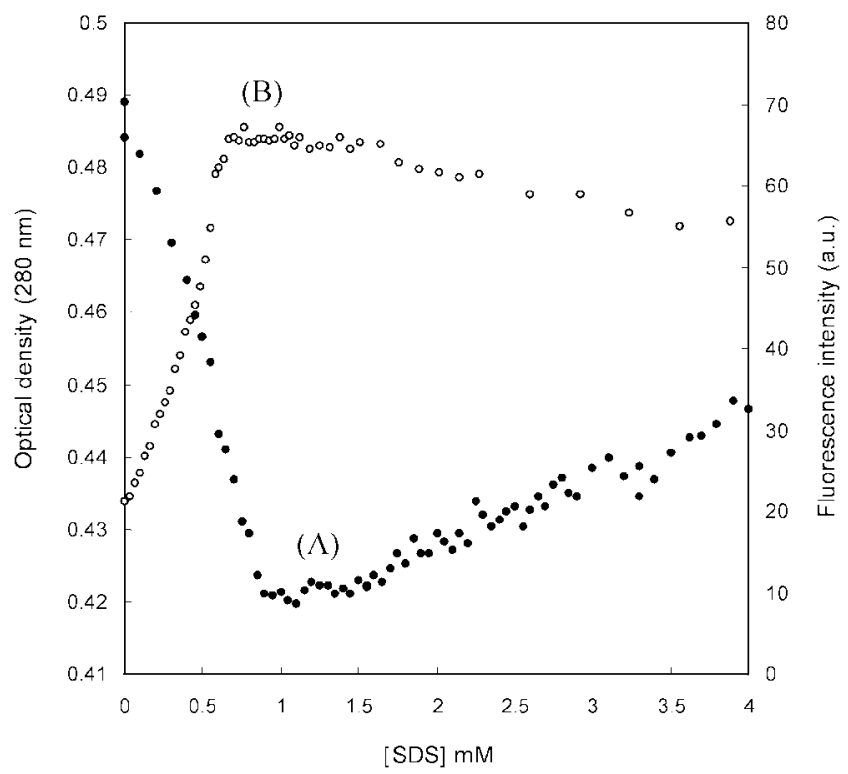

Fig. 3. (A) Changes in hemoglobin absorbance at $280 \mathrm{~nm}$ in the presence of SDS. (B) Changes in Trp fluorescence (arbitrary unit, a.u.) of hemoglobin in the presence of SDS. Excitation and emission wavelengths were $295 \mathrm{~nm}$ and $330 \mathrm{~nm}$ respectively. The slit was $10 \mathrm{~nm}$. The hemoglobin concentration sample was $4 \mathrm{mg}$ / $\mathrm{ml}$ in a $100 \mathrm{mM}$ phosphate buffer, $\mathrm{pH} 7$ at $27^{\circ} \mathrm{C}$.

negative charges on the hemoglobin. These changes in the protein system enhance the electron transfer at the electrode surface and results in an $i_{p}$ increase.

Fig. 3 shows absorbance at $280 \mathrm{~nm}$ and fluorescence intensity (emission at $330 \mathrm{~nm}$ and excitation at $295 \mathrm{~nm}$ ) with changes versus the SDS concentration. The minimal absorbance level and maximal fluorescence level belong to $1 \mathrm{mM}$ SDS. This finding agree completely with previous reports that the Trp fluorescence of hemoglobin increased concomitant with the folding states (Freifelder, 1982). The studies presented here suggest that the folded deoxy structure is responsible for preventing the met formation at low SDS concentrations.

Fig. 4 shows the quenching effects of different concentrations of potassium iodide (KI) in the absence and presence of $1 \mathrm{mM}$ SDS. In this figure, the percent of fluorescence intensities was calculated regarding 100\% fluorescence that is defined for the related samples in which KI was absent. The reduced-quenching effect of potassium iodide (KI), a regular quencher of tryptophane (Trp), in the presence of $1 \mathrm{mM}$ of SDS was also considered the result of the folded deoxyhemoglobin. This folded-compact state does not allow the entrance of iodide ions inside the hemoglobin molecule, which then prevents the quenching effect. Generally, literature has reported that the quenching effect of iodide ions are exerted on the exposed as well as accessibleexited tryptophanyl residues (Freifelder, 1982). In fact, some of the exposed and solvent-accessible Trp residues might be 


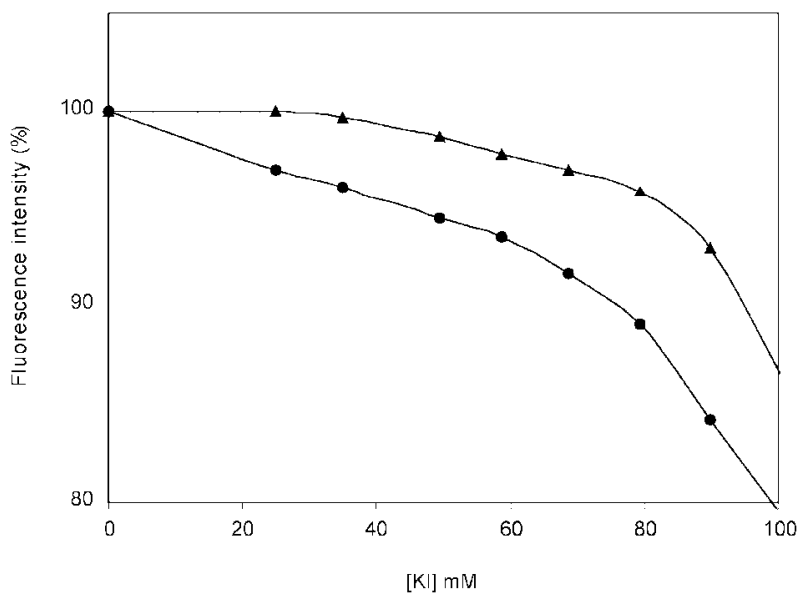

Fig. 4. Quenching effect of KI on hemoglobin samples treated in the presence and absence of SDS. Excitation wavelength was $295 \mathrm{~nm}$, emission wavelength was $328 \mathrm{~nm}$, and the slit was $10 \mathrm{~nm}$ The hemoglobin concentration sample was $4 \mathrm{mg} / \mathrm{ml}$ in a $100 \mathrm{mM}$ phosphate buffer, $\mathrm{pH} 7$ at $27^{\circ} \mathrm{C}$. Filled circle, $0 \mathrm{mM}$ SDS; filled triangle, $1 \mathrm{mM}$ SDS.

inaccessible for the iodide ions regarding the circumferential negative charges of the other residues. If the structural alterations, which occurred for a protein (in a solution containing the iodide ions) in such a way that some of the Trp residues are surrounded by negative charges of other residues, then it will be accompanied by the increment of the fluorescence intensity in comparison to the native structure of the protein. But, we attributed the increment of the SDS fluorescence intensity that contains the hemoglobin solution (relative to the native oxyhemoglobin solution) to the structural compactness of the hemoglobin molecules, which was induced by SDS. This is because low concentrations of the Trp residues are induced rigorously for the SDS-Hb structure, which indicates that the entrance of the tryptophans into the hydrophobic spaces (and not into polar spaces of the negative charges) dissipated inside the protein structure (Fig. 4). Moreover, increasing the iodide concentration resulted in the decrement of the fluorescence of the SDS-Hb solution, which slowed the accessibility of the iodide ions to the hidden Trp residues at higher concentrations. This finding shows the probability of proximity between the hidden Trp residues and the iodide ions that would not be present if the Trp residues were surrounded by negative ions.

Fig. 5 shows the change of partial specific volume for hemoglobin versus SDS concentration. The partial specific volume is at a minimal level in about a $1 \mathrm{mM}$ SDS concentration. The lowest partial specific volume (previously reported) belongs to the more folded state (Kamiyama et al., 1999). This folded compact state may prevent the entrance of water to the heme pocket in order to promote the oxidation process via acting as a nucleophile (Stargardt, Awkridge and Lanrum, 1978; Wallace et al., 1982). This compacted structure has higher stability in contrast to other hemoglobin

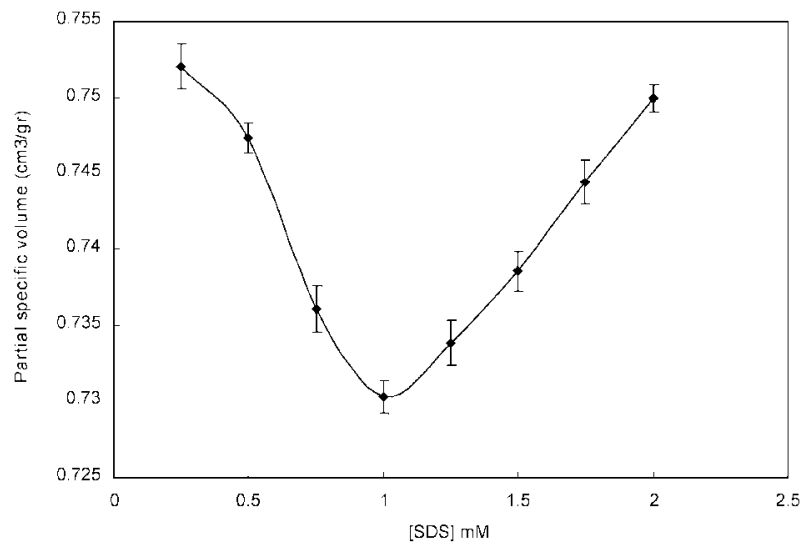

Fig. 5. Effect of SDS concentrations on partial specific volume changes for deoxyhemoglobin at $27^{\circ} \mathrm{C}$ and $\mathrm{pH}$ 7.0.

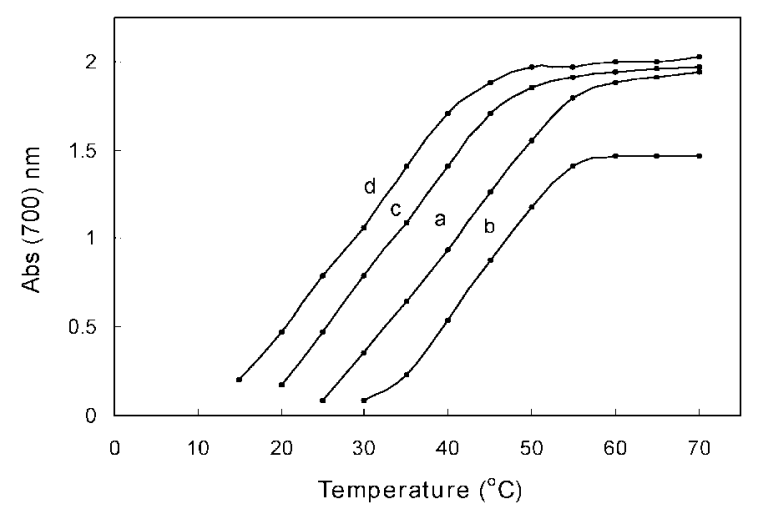

Fig. 6. Absorbance changes of hemoglobin at wavelengths of $700 \mathrm{~nm}$ versus temperature as a measure of turbidity criteria for different SDS concentrations. The maximum point of thermal profile is defined as the melting point $\left(\mathrm{T}_{\mathrm{m}}\right)$. The hemoglobin concentration sample was $4 \mathrm{mg} / \mathrm{ml}$ in a $100 \mathrm{mM}$ phosphate buffer, $\mathrm{pH} 7$ at $27^{\circ} \mathrm{C}$. a) $0.4 \mathrm{mM} \mathrm{SDS}$; b) $1 \mathrm{mM}$ SDS; c) $1.5 \mathrm{mM}$ SDS; d) $2.5 \mathrm{mM}$ SDS.

structures that are shown in thermal profiles, as well as turbidity curves (Figs. 6 and 7).

Fig. 6 shows the absorbance changes at $700 \mathrm{~nm}$ as a protein turbidity criteria versus temperatures of different hemoglobin/ SDS solutions. The inflection point for a curve (b) shows a higher value of temperature midpoint (higher protein stability), which indicates that the turbidity of hemoglobin solution occurs at a higher temperature for $1 \mathrm{mM}$ SDS. This indicates a more stable conformation for hemoglobin under these conditions.

Fig. 7A shows the irreversible thermal unfolding of hemoglobin. The top peaks show the melting temperature $\left(\mathrm{T}_{\mathrm{m}}\right)$ for protein in the absence and presence of SDS (1-2 mM). Figure 7B shows a higher Tm (melting temperature) as the stability criteria for hemoglobin is up to $1 \mathrm{mM}$ SDS. But, in the recorded irreversible thermal transitions, the use of melting temperatures $\left(T_{m}\right.$ as a suitable parameter for ascertaining of the structural stability of the proteins) will be 

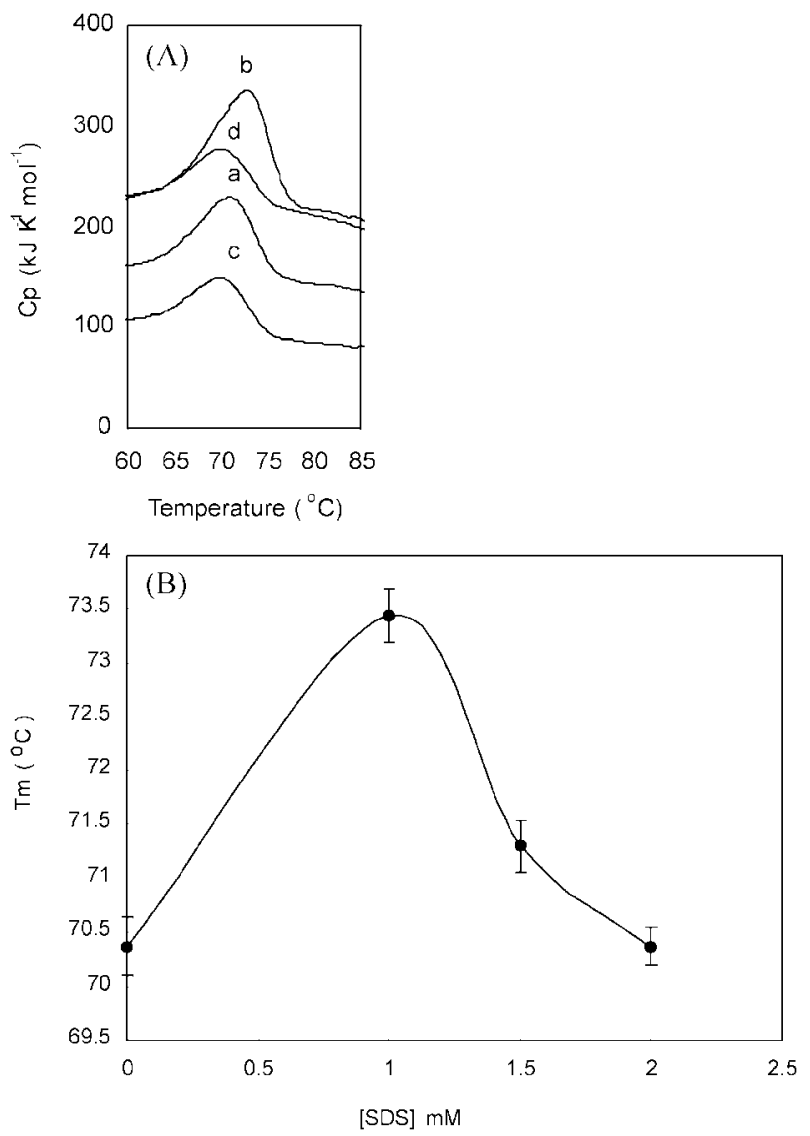

Fig. 7. (A) Melting point (Tm) of hemoglobin against SDS concentrations, a) $0 \mathrm{mM}$ SDS; b) $1 \mathrm{mM}$ SDS; c) $1.5 \mathrm{mM}$ SDS; d) $2 \mathrm{mM}$ SDS. (B) The plot of $\mathrm{T}_{\mathrm{m}}$ versus SDS concentration.

comparatively permissive. This indicates that the structural alterations are occurring on a reference native structure of the desired protein ( $\mathrm{R}$-form of hemoglobin).

In the proposed mechanisms by Robert E. Brantley et al. (Brantley et al., 1993) and others (Kilmartin, 1973; Satoh and Shikama, 1981; Wallace et al., 1982; Shikama, 1984; Faulkner, Bonaventura and Crumbliss, 1995) for myoglobin and hemoglobin autoxidation, the starting species are Fe (II) $\mathrm{O} 2$, where a hydrogen bond between oxygen and the $\mathrm{N} \varepsilon$ atom of distal histidine are present. In the first step of autoxidation mechanism, the disruption of the hydrogen bond and dissociation of hemoglobin and $\mathrm{O} 2$ occur. In the second step, a water molecule associates with hemoglobin (FeII) to occupy the sixth coordination site. In the third step, an electron is transferred from hemoglobin (FeII) to molecular oxygen via an outer sphere mechanism. In this mechanism, if the entrance of water is blocked by any factor (like SDS), then the autoxidation of hemoglobin could be prevented. This is presumably the mechanism by which low SDS concentrations (up to $1 \mathrm{mM}, 50$ molecule of SDS binds to human hemoglobin by electrostatic interactions (data not shown)) can prevent hemoglobin autoxidation. It can then be concluded that low SDS concentrations induce the folded compact state of hemoglobin as a stabilized form of the protein, which prevents met formation, perhaps by water exclusion from the folded protein.

Acknowledgments The authors thank Drs. N. Sheibani and C. M. Sorenson, University of Wisconsin, for their valuable comments on the manuscript. The financial support of the Research Council of the University of Tehran is gratefully acknowledged.

\section{References}

Antonini, E. and Brunori, M. (1971) Hemoglobin and myoglobin in their reaction with ligands, North-Holland Publishing Co., Amsterdam.

Arakawa, T. and Timasheff, S. N. (1982) Stabilization of protein structure by sugars. Biochemistry 21, 6534-6544.

Baldwin, J. N. and Ye, R. P. (1988) Catalytic reduction of myoglobin and hemoglobin at chemically modified electrodes containing methylene blue. Anal. Chem. 60, 2263-2268.

Banerjee, R. and Cassoly, R. (1969) Preparation and properties of the isolated alpha and beta chains of human hemoglobin in the ferri state. Investigation of oxidation-reduction equilibria. $J$. Mol. Biol. 42, 337-349.

Benesch, R. E. Benesch, R. and Yung, S. (1973) Equations for the spectrophotometric analysis of hemoglobin mixtures. Anal. Biochem. 55, 245-248.

Berman, M. Benesch, R. and Benesch, R. E. (1971) The removal of organic phosphates from hemoglobin. Arch. Biochem. Biophys. 145, 236-239.

Bonaventura, C. Tesh, S. Faulkner, K. M. Kraiter, D. and Crumbliss, A. L. (1998) Conformational fluctuations in deoxy hemoglobin revealed as a major contributor to anionic modulation of function through studies of the oxygenation and oxidation of hemoglobin $\mathrm{A}_{0}$ and Hemoglobin Deer Lodge b2(NA2) His $\rightarrow$ Arg). Biochemistry 35, 496-506.

Bordbar, A. K. Moosavi-Movahedi, A. A. and Saboury, A. A. (1996) Comparative thermodynamical stability of bovine and pigeon hemoglobin by interaction with sodium n-dodecyl sulphate. Thermochimica Acta 287, 343-349.

Boyiri, T. Safo, M. K. Danso-Danguah, R. E. Kister, J. Poyart, C. and Abraham, D. J. (1995) Bisaldehyde allosteric effectors as molecular ratchets and probes. Biochemistry 34, 15021-15036.

Brabec, V. (1996) Experimental Techniques in Bioelectrochem. Vol. 3 Birkhäuser Verlag, Germany.

Brantley, R. E. Jr. Semerdon, S. J. Wilkinson, A. J. Singleton, E. W. and Olson, J. S. (1993) The mechanism of autoxidation of myoglobin. J. Biol. Chem. 268, 6995-7010.

Bunn, H. F. and Forget, B. G. (1986) Hemoglobin: Molecular Genetic and Clinical Aspects, Saunders Company, Philadelphia, PA.

Coletta, M. Ascenzi, P. Santucci, R. Bertollini, A. and Amconi, G. (1993) Interaction of inositol hexakisphosphate with liganded ferrous human hemoglobin, direct evidence for two functionally operative binding site. Biochem. Biophys. Acta 1162, 309-314.

Desbois, A. and Bangerjee, R. (1975) Effects of polyvalent anion binding to hemoglobin on oxygen and oxidation-reduction equilibria and their relevance to allosteric transition. J. Mol. 
Biol. 92, 479-493.

Dickerson, L. D. Sauer-Masarwa, A. Herron, N. Fendrick, C. M. and Busch, D.H. (1993) The electron-transfer mechanism of autoxidation for hemoglobin, myoglobin, and their iron (II) cyclidene models. J. Am. Chem. Soc. 115, 3623-3626.

Dickinson, L. C. and Chien, J. C. (1975) Electron transfer between hemoglobin and coboglobin mediated by methylene blue. J. Am. Chem. Soc. 97, 2620-2625.

Dong, A. Huang, P. Caughey, B. and Caughey, W. S. (1995) Infrared analysis of ligand and oxidation induced conformational changes in hemoglobins and myoglobins. Arch. Biochem. Biophys. 316, 893-898.

Faulkner, K. M. Bonaventura, C. and Crumbliss, A. L. (1995) A spectroelectrochemical method for differentiation of steric and electronic effects in hemoglobin and myoglobins. J. Biol. Chem. 270, 13404-13412.

Freifelder, D. (1982) Physical Biochemistry: Applications to Biology, W. H. Freeman and Company, New York, New York.

Gary, R. D. and Gibson, Q. H. (1971) The effect of inositol hexaphosphate on the kinetics of $\mathrm{CO}$ and $\mathrm{O}_{2}$ binding by human hemoglobin. J. Biol. Chem. 246, 7158-7174.

Geraci, S. and Sada, A. (1972) Reactivity of the 93 sulphydryls of human hemoglobin A: influence of the C-terminal residues. $J$. Mol. Biol. 70, 729-734.

Ho, C. Eaton, W. A. Collman, J. P. Gibson, Q. H. Leigh, J. S. Jr. Margoliash, E. Moffat, K. and Scheidt, W. R. (1982) Hemoglobin and Oxygen Binding, Macmillan Press. Ltd. London.

Kamiyama, T. Sadahide, Y. Nogusa, Y. and Gekko, K. (1999) Polyol induced molten globule of cytochrome C: an evidence for stabilization by hydrophobic interaction. Biochim. Biophys. Acta 1434, 44-57.

Kilmartin, J. V. (1973) The interaction of inositol hexaphosphate with methaemoglobin. Biochem. J. 133, 725-733.

MacDonald, V. W. and Charache, S. (1982) Comparison of the effects of lower monohydric alcohol and inositol hexaphosphate on the oxidation of hemoglobin by menadion. Biochim. Biophys. Acta 705, 48-54.

Mansouri, A. and Winterhalter, K. H. (1974) Nonequivalence of chains in hemoglobin oxidation and oxygen binding, effect of organic phosphates. Biochemistry 13, 3311-3314.

Mizukoshi, H. Itoh, M. Matsakawa, S. Mawatari, K. and Yoneyama, Y. (1982) Tryptophan fluorescence of human hemoglobin. Biochim. Biophys. Acta 700, 143-147.

Moosavi-Movahedi, A. A. Rabbani, A. Goodarzi, M. and Goliaei, B. (1989) Thermodynamic studies of the interaction of sodium n-dodecyl sulphate with histone H1. Thermochimica Acta 154, 205-212.

Moosavi-Movahedi, A. A. and Ghobadi, S. (1991) Thermochemical analysis of the interaction between aspergillus niger catalase and sodium n-dodecyl sulphate. Thermochimica
Acta 189, 201-207.

Moosavi-Movahedi, A. A. (1994) Interaction of aspergillus niger catalase with sodium n-dodecyl sulphate. IUPAC 66, 71-75.

Moosavi-Movahedi, A. A. Naderi, G. A. and Farzami, B. (1994) Denaturation behavior of calmodulin in guanidine hydrochloride, urea, sodium n-dodecyl sulphate and dodecyl trimethylammonium bromide. Thermochimica Acta 239, 61-71.

Moosavi-Movahedi, A. A. Nazari, K. and Saboury, A. A. (1997) Denaturation of horseradish peroxidase with sodium n-dodecyl sulphate and dodecyl trimethyl ammonium bromide. Colloid and Surfaces B: Biointerfaces 9, 123-130.

Nazari, K. Saboury, A. A. and Moosavi-Movahedi, A. A. (1997) Enthalpy investigation for elucidation of the transition concentration for the interaction of horseradish peroxidase with surfactants. Themochimica Acta 302, 131-135.

Riggs, A. (1981) Preparation of blood hemoglobins of vertebrates. Methods Enzymol. 76, 5-29.

Safo, M. K. Moure, C. M. Burnett, J. C. Joshi, G. S. and Abraham, D. J. (2001) High-resolution crystal structure of deoxy hemoglobin complexed with a potent allosteric effector. Protein Science 10, 951-957.

Satoh, Y. and Shikama, K. (1981) Autoxidation of oxymyoglobin. A nucleophilic displacement mechanism. J. Biol. Chem. 256, 10272-10275.

Schlereth, D. D. and Mäntele, W. (1992) Redox-induced conformational changes in myoglobin and hemoglobin: electrochemistry and ultraviolet-visible and fourier transform infrared difference spectroscopy at surface-modified gold electrodes in an ultra-thin-layer spectroelectrochemical cell. Biochemistry 31, 7494-7502.

Shikama, K. (1984) A controversy on the mechanism of autoxidation of oxymyoglobin and oxyhaemoglobin: oxidation, dissociation, or displacement? Biochem. J. 223, 279-280.

Skoog, D. A. and Leary, J. J. (1992) Principles of Instrumental Analysis, Saunders College Publishing, $4^{\text {th }}$ ed. New York, New York.

Stargardt, J. F. Awkridge, F. M. and Lanrum, H. L. (1978) Reversible heterogeneous reduction and oxidation of sperm whale myoglobin at a surface modified gold minigrid electrode. Anal. Chem. 50, 930-932.

Wallace, W. J. Houtchens, R. A. Maxwell, J. C. and Caughey, W. S. (1982) Mechanism of autoxidation for hemoglobins and myoglobins. promotion of superoxide production by protons and anions. J. Biol. Chem. 257, 4966-4977.

William, R. C. Jr. and Tsay, K. Y. (1973) A convenient chromatographic method for the preparation of human hemoglobin. Anal. Biochem. 54, 137-145.

Zavodnik, I. B. Piletskaia T. P. and Stepuro, I. I. (1992) Autoxidation and oxygenation of human hemoglobin. Mol. Biol. (Mosk) 26, 321-327. 